\title{
Safe travelling. A trip to Australia and South Pacific Islands
}

\author{
Kornelia Tokarczuk ${ }_{\mathrm{A}, \mathrm{B}}$, Katarzyna Paulina Mazur ${ }_{\mathrm{A}, \mathrm{B}}^{1}$, Katarzyna Van Damme-Ostapowicz ${ }_{\mathrm{E}, \mathrm{F}}$, Elżbie- \\ ta Krajewska-Kułak ${ }_{\mathrm{E}, \mathrm{FE}}$ \\ ${ }^{1}$ Students` Scientific Society “Tropic”, Department of Integrated Health Care, Medical University in \\ Białystok \\ ${ }^{2}$ Department of Integrated Health Care, Medical University in Białystok
}

\section{Review}

Introduction: Nowadays more and more people travel to Australia and the South Pacific Islands. These distant countries are attractive for their exoticism, different culture and unique fauna and flora. Travellers to the islands of Oceania are exposed to many risks, some not found in Europe. Therefore, thorough preparation before a trip to this distant territory is essential.

Aim: The aim of the present review is to acquaint the reader with and sensitize him to the risks found in Australia and the South Pacific Islands. The paper takes into consideration diseases, dangerous animals and recommended vaccination. Appropriate preparation for a trip can protect the traveller from a disease or a disability.

Material and methods: The review is based on the reports of the World Health Organization (WHO), books and publications by authors specializing in tropical and travel medicine as well as scientists, who did research on these issues.

Conclusions: A trip to Australia and the South Pacific Islands does not involve serious risks - health care is well developed there and tourists may rely on help from various institutions. Nevertheless, it should be borne in mind that this territory is not entirely free from contagious diseases. Special attention should be paid to those transmitted by mosquitoes and protection from their bites should be a priority in the preventive health care. We should be especially careful when going to rural, uninhabited areas of poor sanitation and hygiene standards. Failure to comply with basic principles of hygiene can result in food poisonings, trachoma, hepatitis A and B, etc. We should not forget about vaccines recommended for a given country, which are listed in this article. Moreover, the territory of Australia and the South Pacific Islands has unusual fauna that a tourist may not be familiar with and thus may feel vulnerable encountering it. We should be aware of this danger, follow the local recommendations and warnings as well as became acquainted with first aid rules in case we are burnt or bitten by a snake. As far as viral diseases are concerned, apart from protection from mosquito bites, it is also essential to be diagnosed early and so any worrying symptoms should be consulted with a doctor.

\section{Introduction}

Australia and the South Pacific Islands is a territory on the southern hemisphere mostly within the tropical and equatorial climatic zones. It represents diverse climatic conditions. Tropical monsoon forests, savannahs, deserts, steppes, high mountains as well as active volcanoes, geysers and hot springs are found there.

The area is partly an overseas territory of France, Great Britain and the United States. The region is inhabited by over 34 million people dispersed over the territory of 8.5 million $\mathrm{km} 2$. The most densely populated city is Jakarta ( 9.5 million inhabitants). Population density is very uneven. The currency of Australia and the South Pacific Islands is the Australian dollar [1].

The Australian tourism industry and medical care system are well developed. The country is almost completely free from endemic areas however, it is worth to undertake certain precautions, especially when travelling to the rural and scarcely populated areas. This ar- ticle focuses mainly on the issues of health and safety of tourists: vaccination, fauna-related risks, local diseases and their prevention [2].

There are three basic climate zones in Australia: cool, wet winters and dry, hot summers on the south coast, which is the most densely populated area; dry winters and hot, wet summers in the north; and barren regions of central Australia with scarce rainfalls and floods. The climate affects the activities of mosquitoes that transmit various diseases, depending on the season of the year and latitude. It is obvious that the life cycle of mosquitoes is activated during rainy and damp seasons and their population increases. In the south of Australia the highest risk of mosquito-related viral infections is observed from November to January, whereas in the north - from December to May [3]. 


\section{Vaccination}

The only obligatory vaccine for all tourists is the yellow fever vaccine. However, the disease does not pose a risk on the territory of Australia and the South Pacific Islands. Therefore, in the case of trips to this region we can only use recommended, not refunded vaccines $[1,4]$.

The vaccines recommended for foreign travels (in individuals with completed immunization schedules) are as follows:

Viral hepatitis A: Fiji, Guam, Kiribati, Nauru, Niue, New Caledonia, Papua New Guinea, French Polynesia, Samoa, Vanuatu, Solomon Islands, Cook Islands, Marshall Islands, Wallis and Futuna, Northern Mariana Islands.

Viral hepatitis B: Fiji, Australia, Guam, Kiribati, Nauru, Niue, New Caledonia, New Zealand, Papua New Guinea, French Polynesia, Samoa, Vanuatu, Solomon Islands, Cook Islands, Marshall Islands, Wallis and Futuna, Northern Mariana Islands.

Typhoid: Fiji, Guam, Kiribati, Nauru, Niue, New Caledonia, Papua New Guinea, French Polynesia, Samoa, Vanuatu, Solomon Islands, Cook Islands, Marshall Islands, Wallis and Futuna, Northern Mariana Islands.

Japanese encephalitis (during a longer stay, especially on rural territories with poor hygiene standards): Australia, Guam, Papua New Guinea, Northern Mariana Islands $[5,6,7,8,9,10,11,12,13,14,15,16,17,18,19$ ,20].

\section{Food poisoning}

People travelling to Australia and the South Pacific Islands should pay special attention to what they eat and drink to avoid traveller's diarrhoea, although generally the food standards on this territory are high. The development of diarrhoea is affected by the socio-economic status of the area, i.e. by sanitation and hygiene standards in the place of our destination. Thus, the risk of diarrhoea is higher not in the bigger cities of Australia, but in the unpopulated, rural regions of the Australian continent and a number of South Pacific islands. Reef fish (especially carnivorous ones) should be avoided since they can cause poisoning with sea toxins - ciguatera. In general, consumption of water is safe. While travelling in rural and remote areas only bottled water should be drank. It is not recommended to drink directly from streams and rivers; water should be first boiled or otherwise cleaned [2].

Sometimes diarrhoea can be epidemiological in character, especially when it spreads through water, e.g. cholera and salmonella epidemics. In 2009 and 2010 for the first time in history there was an outbreak of cholera epidemic in Papua New Guinea (5039 cases, 79 deaths). The infection did not spread evenly through the island, which was associated with different burial practices, availability of water and hygiene of hands. Due to hindered access to some areas affected by the epidemic (only via planes and boats), the precise count of the affected was not possible [21].

Vaccination against cholera is not recommended. The risk of infection for tourists is low [22].

\section{Malaria}

Most cases of this disease are reported south of Sahara. On the territory of Australia and the South Pacific Islands malaria is found mainly in New Guinea, on Solomon Islands and in Vanuatu. Apart from HIV/ AIDS and tuberculosis, malaria is the most frequent disease, which affects people. Small children and pregnant women are particularly susceptible to infection. The disease is transmitted by four types of plasmodium: Plasmodium vivax, Plasmodium malariae, Plasmodium falciparum and Plasmodium ovale; the majority of cases are caused Plasmodium falciparum and Plasmodium vivax (80-95\%). Their life cycles depend, inter alia, on temperature. In low temperatures the parasite's life cycle stops. In order to develop mosquitoes need water environment, where they lay eggs and where their larvae live.

The life cycle of plasmodium is divided into two stages: sexual (sporogony - in the female mosquito, lasting between 9 and 21 days) and asexual (schizogony - in the human body). The parasites are transmitted to humans when mosquitoes suck their blood (female mosquitoes of about 70 species) and penetrate into erythrocytes and hepatocytes. Moreover, Plasmodium ovale and Plasmodium vivax have a dormant form called the hypnozoite. It can be activated months or even years after the infection. When a human is re-bitten by a female mosquito which sucks into micro- and macrogametes, the parasite's cycle can be completed in the insect's organism.

Malaria starts with an asymptomatic period (liver schizogony and the first blood cell cycle) followed by a symptomatic period. An attack of malaria can be divided into three characteristic stages occurring usually at regular intervals (every 48 or 72 hours): shivering;

1. cold stage - the sensation of coldness and

2. hot stage - high fever (usually above 40 degrees Celsius), feeling hot, dry skin and mucous membranes, disorders of consciousness, coma, abdominal pain related to enlarged spleen;

3. sweating stage - sudden fever drops accompanied by profuse sweating;

Other symptoms are less specific and include gastrointestinal disorders (nausea, diarrhoea, vomiting, gastroenteritis), hyperbilirubinaemia, anaemia, thrombocytopaenia, malaise, confusion.

The infection with Plasmodium falciparum is characterised by irregular fits, severe complications and the highest mortality of $15-20 \%$. 
The diagnosis of malaria is based on detection of malarial parasites in the blood using the thick drop method and Giemsa staining. It is important to repeat the test several times a day, for 3 days, because of the diurnal cycle of Plasmodium [23].

\section{Viral hepatitis}

The most frequent type of hepatitis encountered in Australia and on the South Pacific Islands is hepatitis B. About 4.5 million of Australians travel abroad each year. Frequent destinations are Southeast and East Asia, where the incidence rate of hepatitis B is high. It is estimated that $30-50 \%$ of Australian tourists will get sick or injured during trips. Therefore, while in the countries of Oceania, we should be aware of the risk of hepatitis virus infection. Risky behaviour includes: piercing, tattoos, acupuncture, unprotected sexual intercourses, intravenous drugs and procedures performed at hospitals or at dentist practices. Up to $49 \%$ of travellers will encounter at least one of the risk factors.

Liver disease caused by infection with hepatitis $B$ virus (HBV) is a global problem. According to estimates, 350 million people worldwide are its carriers and 2 billion of currently alive people have been infected with $\mathrm{HBV}$ at some point of their lives. Moreover, $75 \%$ of all chronic carriers live in Asia and on the borders of western part of the Pacific. Approximately $90 \%$ of children infected during the first year of life will develop chronic complications of hepatitis B. Each year about 600 thousand people die due to hepatitis B complications. HBV is present in all bodily fluids of an infected person (except for faeces); therefore, the infection spreads not only through blood but also through semen, saliva, sweat, tears and milk. HBV is a resistant virus and can survive extreme temperatures and humidity. It may be even 100 more infectious than the human immunodeficiency virus (HIV).

The hepatitis B infectious factor is double-stranded DNA of the hepadnavirus group. The incubation period is 4 to 26 weeks ( 2 months, on average). The carrier state is present in approximately $1 \%$ of the infected. Hepatitis fulminant leading to acute liver failure with necrotic lesions develops in less than $1 \%$ of cases, whereas chronic hepatitis in $5-10 \%$ of the affected. In hepatitis B cases, there is a risk of development of hepatocellular carcinoma.

Symptoms of hepatitis B include weakness, jaundice (yellowing of integuments), dark urine, nausea, vomiting and abdominal pain.

Prevention is realized through a vaccine given to children and adults. It is safe and in $95 \%$ protects against the hepatitis B virus.

According to the WHO data, since 1982 the vaccine has been used over a billion times. In 1992, the routine programme of vaccination of children against hepatitis B was carried out only in 31 countries, whereas in 2006 the obligation was present already in 164 countries. Thanks to vaccination programmes, the hepatitis B incidence in children considerably decreased from about $12 \%$ to below $1 \%[24,25,26]$.

\section{Filariasis}

The Global Programme to Eliminate Lymphatic Filariasis that was launched in 1999 under the WHO patronage, contributed to the introduction of mass drug administration (MDA), which enabled generally accessible treatment of people suffering from filariasis. In the countries such as Cook Islands, Kiribati, Niue, Tonga and Vanuatu, a safe threshold level of the incidence of microfilaria was achieved. The specially adjusted interventions were necessary in Caledonia, Palau, Wallis and Futuna where the incidence rate was below $1 \%$ on the national level but on some islands the percentage was exceptionally high. Papua New Guinea constitutes a special challenge. The programme aimed at elimination of filariasis (and malaria) is a priority to WHO. The health care over the ones already affected and suffering from disfiguring consequences of the disease is equally important. In 2009, special health care was introduced on Fiji but other countries still require interventions [27].

The region of South Pacific can be considered susceptible to filariasis for a number of reasons. It has been reported that outbreaks of epidemic returned after the infection was overcome and the mass treatment withdrawn. Moreover, the infection vector - Aedes polynesiensis - is active during the day and can reproduce in the hideouts of crabs, thus the methods of its control are ineffective. Frequent migrations of islands' inhabitants are likely to contribute to the occurrence of disease on the territories where mass drug administration has not been introduced. Finally, it is difficult to determine whether the risk of infection has been eliminated because the distribution of infection is uneven and can differ even between the neighbouring cities. Hence, the incidence rate in the group studied does not necessarily reflect the incidence rate in the entire population [28]

\section{Trachoma}

Trachoma is a contagious eye infection caused Chlamydia trachomatis. Recurring infections may cause scars on the eyelids and inward turning of the eyelashes leading to blindness. Australia is the only developed country in the world where the problem of trachoma still exists. It spreads on the Aborigines, the Torres Strait Islands, South and West Australia. Children are particularly vulnerable. Trachoma can be transmitted by direct contact of the eye with the bacterium (e.g. during playing) through fingers, everyday use objects, flies sitting on a child's face. Good hygiene is therefore extremely important, especially of the face and the eye area [29]. 


\section{Infection risks in water and on land}

1. Schistosomiasis and leptospirosis The non-human variant of schistosomiasis is widespread on the north coast of Australia. The infection spreads through the skin during wading or swimming. It may cause cercarial dermatitis, although more serious variants of this disease (e.g. the Katayama's fever) seldom appear in infections with the non-human variant of schistosomiasis.

During mountain river rafting it should be remembered that Australia is not free from leptospirosis and drinking water directly from rivers should be avoided. Any wounds or abrasions through which microorganisms causing leptospirosis can enter the body should be covered [2].

\section{Crocodiles}

The territory of Australia is inhabited by saltwater crocodile - Crocodylus porosus. It is a giant reptile similar to alligator but far more dangerous. Its attacks can cause severe wounds or even death but can be avoided. The crocodile-inhabited areas are usually marked. Tourists should pay attention and look for places designated for swimming [2].

\section{Burns}

Another risk is connected with box jellyfish (when seen from above they have a square shape), apalochlaena octopuses (covered with characteristics blue rings) and conidae. To prevent burns while diving or swimming we should avoid touching these animals, or even rocks, which can be camouflaged poisonous animals. While walking on a beach, we should be careful not to step with a bare foot on the dried remains of water animals [2].

First aid after the attack by a marine animal should depend on the condition of the injured individual. Firstly, we should reach the shore and; if required, resuscitation should be carried out. Bleeding, if not life threatening, should not be staunched (since it helps the organism to remove the poison). Horns in wounds should be removed carefully, using rubber gloves. The wound can be rinsed with seawater and subsequently poured over with hot water for several minutes until the pain has subsided. Hot acid solutions can also be used. The wound should always be disinfected and dressed. In cases of contact with poisonous animals, it is always necessary to visit a doctor [30].

\section{Sharks}

In the years 1996-2000, on the territory of Australia 6 individuals died and 12 were injured during shark attacks. Sharks live in nearly every state of Australia. People should swim only in guarded places and follow the instructions of lifeguards [2].

\section{Venomous snakes}

In Australia 5 thousand people die from bites of venomous snakes each year. The introduction of venom manifests itself with pain in the bitten area, swelling and reddening. Toxin causes breathing difficulties, muscle paresis, hypersalivation, nausea, fainting, nosebleeds, urinary tract bleeding, and urine retention.

This terrain abounds in many species of venomous snakes, including: Eastern Brown Snake, Coastal Taipan (called the most venomous snake in the world), Pseudechis Australis (Mulga Snake), Common Death Adder, Red-Bellied Black Snake and Tiger Snake. They generally avoid people, although we can get bitten accidentally stepping on a snake or entering its mating territory [2].

When bitten it is necessary to put a tourniquet on the limb above the wound, which will delay the spread of the venom and increase its outflow from the wound. Skin should not be incised and blood sucked out. The tourniquet should be released every 10-20 minutes for 1-2 minutes during 2 hours. The wound should be dressed with sterile bandage and the limb immobilized. The patient should avoid unnecessary movements. It is essential to reach a medical centre as soon as possible to administer serum. It is also crucial to identify the snake, so, if possible, you should take it with you [31].

\section{Spiders}

Spiders are small and can bite without the injured realizing it so it is important to remain vigilant. In Australia you can encounter species such as Latrodectus Hassetti - redback spider (a cousin of black widow) and Sydney funnel-web spider (Atrax robustus). Spiders are found also in municipal areas in New South Wales and on the east coast [2].

\section{Acari and ticks}

Scrub Typhus (Japanese River Fever) which is present in north-east Australia manifests itself with fever, rash and characteristic scabs. It may be caused by a bite from a young acari or a flea infected with Rickettsia tsutsugamushi (Orientia tsutsugamushi). People walking in the thicket should wear impregnated clothes covering legs and use insect repellents. If a visible reaction appears on the skin within 24-48 hours following a tick's bite, we should see a doctor [2].

The case of the famous Crocodile Hunter Steve Irwin is well known. In 2006, during a shooting of one of his documentaries, he was injured by a stingray. Steve was struck in the chest by the stingray's barb, which led to numerous internal injuries and death [32]. 


\section{Viruses}

Many viruses present in Australia and on the South Pacific Islands are also found in other parts of the globe. This article focuses on those most threatening for tourists. Due to the expansion of adventure tourism, travellers should be aware of the risk of infection with Australian viruses, which may cause a number of diseases.

The most numerous viruses are those of the alphavirus type, especially Ross River Virus and Barman Forest Virus. They mainly cause joint pain, with or without fever and rash. Viruses that are more dangerous are less common. They include Murray Valley Encephalitis Virus and Kunjin Virus, Dengue Virus present periodically in the northern part of Queensland state and recently also Japanese Encephalitis on the Torres Strait Islands and the cape of the north Queensland.

Viruses carried by bats, such as rabies virus or Hendra virus are less dangerous [3].

\section{Dengue Virus}

A relatively new threat is connected with the dengue virus spreading dramatically over new territories. The disease is present mainly in municipal areas, where improperly stored food and problems with recycling of wastes favour the reproduction of mosquitoes - infection vectors. Urbanization thus leads to an increase in their number, which in turn increases the risk of the outbreak of dengue fever [33]. The situation is also worsened by the intensification of international travelling - especially to the Dengue fever endemic regions, such as the southeast countries of Asia neighbouring Australia [3].

The disease may be transmitted only by a mosquito bite, especially from the Aedes aegypti species. Sporadically the involvement of apes is also reported.

The dengue virus, like yellow fever virus, belongs to the genus Flavivirus. The two viruses show cross-resistance and therefore the incidents of dengue fever and yellow fever do not occur in the biotope simultaneously, contrary to those types of dengue virus, in the case of which, theoretically, it is possible to be infected with all types. No vaccine preventing the infection has yet been developed [34].

Several years after a big dengue fever epidemic of 1998, West Pacific member countries reported increased incidence rates - 100000 in 2001-2002 and 200000 in 2007. In 2009, countries such as American Samoa, Cook Islands, French Polynesia, New Caledonia registered high incidence rates of dengue cases [35]. North Australia in the Queensland state is considered an endemic area of dengue fever [36].

Reactivation of dengue fever is a worldwide health problem. Due to the increase in the number and types of vectors, the region in question became prone to reappearance of the epidemic. Aedes aegypti is most common in the state of Queensland; however other infection vectors are also becoming a serious problem e.g. Aedes albopictus which spreads dengue fever on
Torres Strait Islands. Due to forecasted climatic changes, dengue fever is expected to spread southwards, for instance to New South Wales [37].

Dengue fever is thus one of the diseases that should be taken into account in differential diagnosis of fever in individuals returning from Australia and the South Pacific Islands, especially during an epidemic. The symptoms that should raise suspicion include severe headaches, retro-ocular pain, muscle and joint aches, nausea, vomiting, swollen lymph nodes or rash. In general, the symptoms persist for 2-7 days, following the 4-10day virus incubation [38].

Re-infection with another type of dengue virus may result in an extremely dangerous form of disease dengue hemorrhagic fever and dengue shock syndrome - DHF/DSS, which eventually leads to hemorrhages to the body cavities with symptoms of shock, loss of consciousness and even death [34]. After an over 100-year absence, the fatal cases caused by DHF/DSS reappeared in Australia. Therefore, tourists with the history of dengue fever should avoid trips to the areas where the virus can be found $[3,37]$.

\section{Ross river fever ( RRF)}

Ross River fever is the most common endemic disease of Australia and South Pacific Islands caused by a virus from the alphavirus family. The first mention of arthritis, most likely related to the Ross river virus infection, was described in east Australia and New Guinea at the turn of the 19th and 20th centuries. In 1996, RRF was for the first time identified in a mosquito and linked to the occurrence of arthritis epidemic. Three genotypes of the virus were described; however, it is the genotype 2 that is responsible for the majority of infections. The two main species of mosquitoes connected with RFF are Aedes vigilax and Aedes camptorhynchus. The virus is not transmitted from one person to another. The number of the infected ranges from 2000 to 8000 annually.

Ross River fever attacks not only humans but also other mammals (mainly marsupials, and very rarely - horses, dogs and pigs). The infection may appear at any age (usually between 25 and 44 years of age), depending on the exposure, although it seldom appears in children. The incubation period lasts 3 to 21 days. The majority of RRF infections proceed asymptomatically. The symptoms include gastrointestinal disorders, fatigue, muscle pain, slight fever. Rash can develop after several days. The most characteristic symptoms are symmetrical stiffness and swelling, mainly of small joints in the upper and lower limbs (80-90\% of the infected). Tendinitis and chronic headaches can also be present. Severe inflammatory joint symptoms develop when inflammatory mediators are released from the infected monocytes/macrophages. Recovery lasts up to one month. In $10 \%$ of the affected, severe arthritis symptoms can persist longer. Complete recovery may take months, even years. A rare complication is glomerulonephritis. Arthritis regresses leaving no permanent damage to health. RRF has not been found 
to cause encephalitis. Those affected by the disease are protected against a given viral genome type.

The diagnosis is based on detection of IgM and IgG antibodies. Moreover, increased CRP levels and absence of a rheumatoid factor (RF) in joint involvement ( $\mathrm{RF}$ enabling to differentiate it from rheumatism) are observed.

\section{Barmah forest virus (BFV) and sindbis virus}

It is a mosquito-transmitted virus. Its clinical symptoms are similar to those of RRF. In the course of BFV the rash usually persists slightly longer, whereas changes in the joints are less severe. About 25 to $30 \%$ of individuals diagnosed with Ross River virus were in fact infected with BFV. Sindbis virus is an alphavirus present in other parts of the world as well (e.g. in the USA, Scandinavia, Africa). The virus is transmitted to humans by vertebrates, mainly birds [3].

\section{Murray valley encephalitis virus (MVEV)}

MVE is a viral disease caused by the flavivirus and transmitted by Culex annulirostris mosquitoes. It was first mentioned in the report on encephalitis on the east coast of Australia at the beginning of the 20th century. In the 1950s and 70s, two outbreaks of MVEV epidemic were reported. The highest incidence rates were reported for Kununurra in the Kimberley region (north-west Australia) and for northern Tanzania. The virus is connected with Culex annulirostris mosquitoes, migratory water birds as well as some marsupials and mammals. The disease spreads through the regions characterized by heavy rainfalls and floods. The virus incubation period lasts up to 4 weeks. Many infections develop asymptomatically, non-specifically or only with fever; therefore, the actual incidence rate of MVE is difficult to be determined accurately. According to estimates, 1000 1500 individuals are infected annually. The virus cannot be transmitted from one person to another [39].

In children MVE manifests itself in a sudden onset with high fever and seizures whereas in adults in fever, headaches and mood swings. Cranial nerve palsies, muscle rigidity and tremors are the symptoms indicating flavivirus gray matter involvement. Moreover, changes are found in the spinal cord, and those within the central nervous system can be observed in magnetic resonance imaging (MRI) and computed tomography. In some patients the course of the disease is severe; respiratory failure, consciousness disorders and laccid paralysis are observed in severe paediatric cases. The mortality rate is $20 \%$, and half of individuals who had MVEV infections experience permanent neurological damage.

Prevention involves mainly the use of mosquito nets, mosquito repellents and appropriate clothes.

\section{West nile virus (wnv) - kunjin virus (kunv)}

WNV was first discovered in northern $\mathrm{Qu}$ eensland, but it also spreads along northern Tanzania and western Australia. Its enzootic cycles are similar to those of MVEV.

At first the Kunjin virus was believed to be a separate virus type yet was later classified together with the West Nile virus. The difference between the two is that the Kunjin virus does not cause the death of birds and horses, and has less severe effects on people.

It can cause encephalitis. Ten cases without encephalitis and with or without fever were reported. The majority of infections is asymptomatic or causes very mild, non-specific symptoms. The infection should be suspected in the case of any neurological symptoms acquired in Australia.

\section{Japanese encephalitis}

The disease is common in Asia, including the immediate neighbours of northern Australia. Although until recently Australia was free from this disease, clinical cases were reported on the Torres Strait Islands (between Australia and New Guinea) in 1995. The infection was found to be endemic. After introduction of vaccination, control of mosquitoes and transportation of pigs in 1998 only one case was reported on the islands. The same year there was one death reported in Queensland, most likely due to spreading of the infected mosquitoes by the wind. The disease reappeared there several times but the enzootic focus has not been found in this area. Nevertheless, the risk remains, especially that Australians frequently visit the countries where Japanese encephalitis occurs endemically.

\section{Koko bera}

It was first isolated in north Queensland, New South Wales, Victoria and eastern and western Australia. Contrary to other flaviviruses, this one is commonly reported in south, moderate climate regions as well as north of Australia.

Human infections are extremely rare and manifest themselves with muscle and joint pain.

\section{Bunya viruses}

Humans have been reported to be sporadically infected with Gan Gan and Trubanam bunya viruses.

\section{Bat-transmitted viruses}

Hendra virus was first detected in 1994, when it was found to be an etiologic factor responsible for a severe respiratory disease in racing horses, which led to two human infections on the outskirts of Brisbane.

The virus was demonstrated to be transmitted by fruit bats, although horses can also be involved. The mechanism of transmission from a bat to a horse is not known.

Australia is believed to be rabies-free; however, since 1996, there have been some cases of the rabies vi- 
rus transmitted by bats - all of them fruit bats and at least one insectivorous. Nevertheless, the risk for tourists is extremely low. To prevent the development of disease, it is essential to avoid bats that are alive and those dead for less than four hours. Vaccines are recommended only for wildlife carers and vets. After a bite or a scratch, the wound should be carefully cleansed and the injured should see a physician to have the vaccine and antibodies administered. Whenever possible, the bat should be caught and sent to the Australian Animal Health Laboratory in Geelong, Victoria.

\section{Tourists returning from Australia with a suspicion of arbovirus infection}

Tourists returning from Australia with fever should seek medical attention. The virus incubation period is relatively short; tourists usually develop symptoms within 1-2 weeks, and almost certainly within a month after infection. The main symptoms include arthritis with or without fever and rash. It is important to determine the country and region the tourist visited, his/her activities, season of the year, exposure to mosquitoes, wild and domestic birds and livestock. The other risk factors are sexual contacts and intravenous drugs.

Tourists with fever, rash and joint aches returning from Queensland may be suspected of infections with Ross River fever, Barman Forest virus, dengue virus, Kunjin virus, leptospirosis and rickettsia.

When the same symptoms develop after a visit to north-west Australia, the only suspects are RRV, BFV or less likely Kunjin virus.

\section{Prevention and treatment of alphaviruses}

Although the risk is extremely low, it is worth to present tourists with preventive measures. There are no vaccines against alphaviruses.

Prevention is based on raising awareness in people exposed to the risk of infections transmitted by mosquitoes. Early detection of the first symptoms and immediate medical interventions are crucial. The cheapest and the most effective method of protection against infections is the use of mosquito nets. Moreover, mosquito repellents, light-colour clothes covering as much skin as possible and limitation of evening activities are recommended. The best repellents contain DEET or picaridin. The DEET concentration of $30-50 \%$ provides protection for several hours. In the case of picaridin 7-15\%, its applications should be more frequent. Repellents with DEET are not recommended for children below the age of 2 months.

The environmental conditions in Australia as well as the number and species of mosquitoes are monitored on a regular basis. The information gathered is needed to prepare warning messages and to provide advice concerning risks. It is essential that the recommendations be observed.

\section{Summary}

A trip to Australia and the South Pacific Islands does not present serious risks, but is it important to take certain precautions. The majority of diseases is mosquito-transmitted and therefore prevention from insect bites is crucial. The area is inhabited by various animals, which pose a risk to our health and life. Any disturbing symptoms developing during our stay abroad and after return home should be alarming [3].

In case of any doubts, it is recommended to see a local general practitioner and keep the receipt to be reimbursed by health insurance. Doctors often speak other languages than English and the main telephone network has a service providing translation in over 15 languages. Bigger cities have travel clinics and the locals willingly provide us with any information concerning medical care. Generally, the area is classified as highly developed, but trips to rural and uninhabited regions should keep us alert [2]

\section{List of abbreviations:}

HIV- human immunodeficiency virus

AIDS - acquired immune deficiency syndrome

HBV- hepatitis B virus

DNA- deoxyribonucleic acid

WHO - World Health Organisation

MDA - mass drug administration

DHF/DSS - dengue hemorrhagic fever/ dengue shock syndrome

RRV- Ross River virus

IgM - immunoglobulin $\mathrm{M}$

IgG - immunoglobulin $G$

CRP - C-reactive protein

$\mathrm{RF}$ - rheumatoid factor

BFV- Barmah Forest virus

MVEV - Murray Valley encephalitis virus

The paper presented during the VI Podlasie Scientific Conference "CHALLENGES OF MODERN MEDICINE , Białystok 2012

\section{References}

1. Dąbrowiecki Z., Geografia chorób zakaźnych [w:] Zarys medycyny tropikalnej. Olszański R., Morawiec B., Dąbrowiecki Z., Korzeniewski K., (red).Polskie Wydawnictwo Medycyny i techniki Hiperbarycznej, Gdynia 2006: 45-46

2. Shaw MMT,. Leggat PA..Country profile: Travelling to Australia. Travel Med Infect Dis 2003,1:126-133

3. Smith DW, Spears DJ i wsp. The viruses of Australia and risk to tourism. Travel Med Infect Dis, 2011, 9:113125

4.Morawiec B, Jerzemowski J. Szczepienia ochronne. [w:] Zarys medycyny tropikalnej. R.Olszański, B.Morawiec, Z,Dąbrowiecki,K.Korzeniewski (red).Polskie Wydawnicstwo Medycyny i techniki Hiperbarycznej, Gdynia 2006: 51 
5.http://www.traveldoctor.com.au/travelreport. asp? UnqID $=0.8146784 \&$ ReportID $=936843 \&$ ReportType $=3 \&$ nav $=$ personal-traveller $-2012-02-22$

6.http://www.traveldoctor.com.au/travelreport. asp?UnqID $=0.362591 \&$ ReportID $=939138 \&$ ReportType $=3 \&$ nav $=$ personal-traveller 2012-02-22

7.http://www.traveldoctor.com.au/travelreport. asp? UnqID $=0.4813806 \&$ ReportID $=936697 \&$ Report Ty$\mathrm{pe}=3 \&$ nav $=$ personal-traveller 2012-02-22

8.http://www.traveldoctor.com.au/travelreport.

9.http://www.traveldoctor.com.au/travelreport. asp?UnqID $=0.7839777 \&$ ReportID $=936699 \&$ Report Type $=3 \&$ nav $=$ personal-traveller 2012-02-22

10.http://www.traveldoctor.com.au/travelreport. asp? UnqID $=0.1795618 \&$ ReportID $=936701 \&$ Report $T y-$ pe $=3 \&$ nav $=$ personal-traveller 2012-02-22

11.http://www.traveldoctor.com.au/travelreport. asp? UnqID $=0.284588 \&$ ReportID $=939139 \&$ ReportType $=3 \&$ nav $=$ personal - travellerBrak 2012-02-22

12.http://www.traveldoctor.com.au/travelreport. asp?UnqID $=0.8503076 \&$ ReportID $=939140 \&$ ReportType $=3 \&$ nav $=$ personal-traveller 2012-02-22

13.http://www.traveldoctor.com.au/travelreport. asp? UnqID $=0.1166498 \&$ ReportID $=936705 \&$ ReportType $=3 \&$ nav $=$ personal-traveller 2012-02-22

14.http://www.traveldoctor.com.au/travelreport. asp? UnqID $=0.83659 \&$ ReportID $=936707 \&$ ReportTy pe $=3 \&$ nav $=$ personal-traveller 2012-02-22

15.http://www.traveldoctor.com.au/travelreport. asp? UnqID $=0.2886164 \&$ ReportID $=936709 \&$ Report Type $=3 \&$ nav $=$ personal-traveller 2012-02-22

16.http://www.traveldoctor.com.au/travelreport. asp? UnqID $=0.8974268 \&$ ReportID=936711\&ReportType $=3 \&$ nav $=$ personal-traveller 2012-02-22

19.http://www.traveldoctor.com.au/travelreport.

20.http://www.traveldoctor.com.au/travelreport.

$02 \&$ ReportID $=936723 \&$ Report Type $=3 \&$ nav $=$ personal -traveller 2012-02-22

21.http://www.who.int/cholera/countries/PapuaNewGuineaCountryProfile2010.pdf 2012-02-22

22.http://www.mdtravelhealth.com/destinations/oceania/papua_new_guinea.php, 2012-02-22

23.Morawiec B. Malaria .[w:] Zarys medycyny tropikalnej. R.Olszański, B.Morawiec, Z,Dąbrowiecki,K.Korzeniewski (red).Polskie Wydawnicstwo Medycyny i techniki Hiperbarycznej, Gdynia 2006: 111-120.

24.http://www.abs.gov.au/ausstats/abs@.nsf/bb8db737e2af84b8ca2571780015701e/B45717BA3C781964CA25723600050EE4?opendocument 2012-0222

25.Crawford JM.Wątroba i drogi żółciowe. [w:]Robbins Patologia. Kumar V, Cotran SR, Robbins SL (red). Wydawnictwo Medyczne Urban \& Partner, Wrocław 2003, 688-689

26. Leggat PA, Zwar NA i wsp. Hepatitis B risks and immunisation coverage amongst Australians travelling to Southeast Asia and East Asia. Travel Med Infect Dis.2009,7: 344-349
2 7.http://whqlibdoc.who.int/publications/2010/9789241500722_eng.pdf 73-74

28. Huppatz C, Durrheim D i wsp. Eliminating lymphatic filariais-the surveillance challenge. Trop Med Int Health. 2008,13:292-294

29.http://www.vision2020australia.org.au/news-eventsnews.cfm?id=1837\&t=/trachoma-in-australia-new-findings/- 2012-02-22

30. Siermontowski P, Olszański R, tyblewski R. Zwierzęta bezkręgow wód tropikalnych niebezpieczne dla człowieka. [w:] Problemy zdrowotne w tropiku. Olszański R. (red). Zakład Medycyny Morskiej i Tropikalnej Wojskowego Instytutu Medycznego, Warszawa 2009: 87-88 31. Kurczewski R. Niebezpieczne gady w tropiku.[w:] Medycyna i higiena tropikalna. Kotłowski A (red). Międzywydziałowy Instytut Medycyny Morskiej i Tropikalnej Akademii Medycznej w Gdańsku, Gdynia 2006:1184-1186

32.http://www.time.com/time/world/article/0,8599,1531446,00.html 2012-02-19

33. WHO, Dengue [w:] Working to overcome the global impact of neglected tropical diseases :

first WHO report on neglected tropical diseases. Geneva 2010: 41

34.Konarski M. Wirusowe gorączki krwotoczne.[w:] Problemy zdrowotne w tropiku. Olszański R. (red). Zakład Medycyny Morskiej i Tropikalnej Wojskowego Instytutu Medycznego, Warszawa 2009:210-212

35.http://www.wpro.who.int/health_topics/dengue/ 2012-02-19

36. http://www.pis.gov.pl/?dep=869 2012-02-19

37. Leggat PA. Dengue in northern Queenisland, Australia: Risk from travellers or risk to travelers? Travel Medicine and Infectious Disease 2009,5:194-195 38.http://www.who.int/mediacentre/factsheets/fs117/ en/ 2012-02-26

39. http://www.health.nsw.gov.au/factsheets/infectious/ murray_valley_enceph.html 2012-02-26

\section{Correspondence address:}

dr hab. n.zdr. Katarzyna Van Damme-Ostapowicz Kierownik: prof. dr hab. med. Elżbieta Krajewska-Kułak Zakład Zintegrowanej Opieki Medycznej

Uniwersytet Medyczny w Białymstoku

ul. M. Curie-Skłodowskiej 7a

15-096 Białystok, Poland

Tel/fax +48 85/ 7485528

email: katarzyna.ostapowicz@gmail.com 